the lattice spacing slightly, whilst the blue colour is formed and then destroyed again. A detailed account cannot be given here, but it may be stated that there is also a slight variation in lattice spacing between members of each class, owing to the differences in size of the alkali atoms.

In addition, blues containing no alkali have been prepared, and X-ray photographs show that the Fe-CN skeleton structure is cubic and similar to that already described. ( $a=10 \cdot 2 \mathrm{~A}$. approx. $)$ Here it seems that additional iron, or iron in combination with a negative ion, can replace the alkali metal. The water content of these blues is unusually high.

The unoxidised analogues of these alkali-free blues have a structure different from any yet described, and are at present under examination. The exact measurement of lattice spacings, water contents, etc., is now proceeding. It is hoped to publish this work elsewhere in more detail.

Most of the analyses were made in the Company's Dyestuffs Laboratory at Blackley.

$$
\text { J. F. KEgGIN. }
$$

Research Laboratories,

F. D. Mrles.

\author{
Imperial Chemical Industries Ltd, \\ Ardeer, \\ Ayrshire. \\ Feb. 29.
}

${ }^{1}$ Howe, J. Amer. Chem. Soc., 18, 983 (1896).

\section{The Ultra-Violet Spectrum of Hæmoglobin Derivatives and Bile Pigment}

As a result of numerous investigations of the ultra-violet spectrum of hæmoglobin and its derivatives, the location of an absorption band in the region of $4100 \mathrm{~A}$. has been established for these compounds. It appears to be due to the hrem radical, and is independent of the nature of the globin fraction.

The ultra-violet spectrum has been quantitatively investigated by me of a number of hæmoglobin compounds which have all been prepared from recrystallised horse hæmoglobin. Those investigated were : oxyhæmoglobin, reduced hæmoglobin, neutral methæmoglobin, alkaline methæmoglobin, carboxyhæmoglobin, acid hæmatin, alkaline hæmatin (in aqueous and alcoholic solutions), reduced alkaline hæmatin, pyridine hæmochromogen, oxidised alkaline hæmatin pyridine, piperidine hrmochromogen and hæmatoporphyrin. All show the characteristic band in the region of $4100 \mathrm{~A}$., although the position of the band is slightly shifted in some of the compounds. The solvents also have a slight influence on the position of the main band. However, its general form and position appears centred at $4100 \mathrm{~A}$. This band is obviously not influenced by the presence of the globin fraction as the hæmoglobin and hæmatin spectrum are quite similar. Nor does the iron in the molecule in any state of oxidation exert any effect since hæmatoporphyrin, the iron-free derivative, has essentially the same absorption spectrum as hæmoglobin.

On the other hand, the ultra-violet absorption of pure bilirubin reveals a very different spectrum. There is no characteristic band at $4100 \mathrm{~A}$. but a rather indefinite absorption extending from $5000 \mathrm{~A}$. to around $4300 \mathrm{~A}$.

Attempts to correlate the structure of the hæm radical and its ultra-violet spectrum are not numerous.
Holden and Hicks ${ }^{1}$ postulate that the main absorption band is present only when the pigment molecules are widely separated or when the valencies of the iron atom are fully utilised. Certainly, solution of the pigments in different solvents with the resultant change in dispersion influences the spectrum of the hæm pigments, but only to a slight degree, and does not explain the presence of the band as a characteristic of the hrm radical. It is impossible to cause the absorption band to disappear by changing the dispersion of the pigment. The only condition under which it will disappear is to convert the hæm nucleus into a bile pigment which involves molecular rearrangement.

A study of our results leads to the hypothesis that the absorption band at $4100 \mathrm{~A}$. in hæm compounds is due to the porphyrin ring system made up of four substituted pyrrol nuclei. In the bilirubin, which is formed by the breakdown of the hæm molecule, the porphyrin ring system is opened into a straight chain of substituted pyrrol nuclei and the absorption which is characteristic of the ring system disappears.

Investigation of the ultra-violet spectrum of other bile pigments is being undertaken in order to confirm this hypothesis.

Department of Biochemistry, University of Western Ontario,

Medical School,

London, Canada. Feb. 5 .

${ }^{1}$ Holden, H. F., and Hicks, C. S., Aust. J. Exp. Biol. and Med. Sci., 10, 219 (1932).

\section{Induced Radioactivity of Nickel and Tin}

IN the course of an investigation, it was found desirable to build Geiger-Müller counters with substances that are not activated by neutron bombardment. From the list given by Fermi ${ }^{1}$ and his collaborators, nickel and tin were selected as the most suitable elements that do not become radioactive when bombarded with neutrons.

When such counters were filled with air and irradiated with slow neutrons from a radon-beryllium source of about 100 me., they were found to show considerable activity. The following half-life periods were found :

$$
\begin{aligned}
& \mathrm{Ni}: 3^{\mathrm{h}} \pm 10^{\mathrm{m}} . \\
& \mathrm{Sn}: 8^{\mathrm{m}} \pm 2 ; 18^{\mathrm{m}} \pm 2 .
\end{aligned}
$$

Rotblat $^{2}$ reported very weak activity with a $20^{\mathrm{m}}$ period when nickel is bombarded with fast neutrons. He irradiated a thin nickel sheet with a radonberyllium source of $40 \mathrm{me}$. and found an initial activity of 1.5 kicks a minute. With fast neutrons, we could, however, detect no activity either of nickel or of tin, even though sources up to $250 \mathrm{mc}$. were employed.

The initial activity of a nickel counter of $2 \mathrm{~cm}$. diameter, $15 \mathrm{~cm}$. long and with walls $0.5 \mathrm{~mm}$. thick was about 60 kicks a minute above the zero count, of 40 a minute, when the irradiating source was about 100 me. strong. With a similar source the initial activity of a tin counter of nearly the same dimensions was about 50 kicks a minute.

To compare these activities with that of a known active element, a tube of copper-nickel alloy, the copper content of which was chemically analysed and found to be 55 per cent, was made into a counter and irradiated with slow neutrons. The intensities 